\title{
Implications of Blood Type for Ovarian Reserve and Infertility - Impact on Oocyte Yield in IVF Patients
}

\author{
Auswirkungen des AB0-Blutgruppensystems auf die ovarielle Reserve und \\ Infertilität - der Einfluss der Blutgruppenzugehörigkeit auf die Oozyten und \\ die Ausbeute bei der kontrollierten ovariellen Stimulation bei IVF Patienten
}

Authors

Affiliations
D. Spitzer ${ }^{1}$, C. Corn ${ }^{1}$, J. Stadler ${ }^{1}$, B. Wirleitner ${ }^{2}$, M. Schuff ${ }^{2}$, P. Vanderzwalmen ${ }^{2}$, F. Grabher ${ }^{2}$, N. H. Zech ${ }^{2}$

${ }^{1}$ IVF Zentren Prof Zech Salzburg, Salzburg, Austria

2 IVF Zentren Prof Zech Bregenz, Bregenz, Austria

Key words
reproductive medicine
ISCI
IVF
o hormones
Schlüsselwörter
- Reproduktionsmedizin
ISCI
- IVF
- Hormone

received $\quad 5.6 .2014$ revised 29.7.2014 accepted 29.7.2014

\section{Bibliography}

Dol http://dx.doi.org/ 10.1055/s-0034-1383045 Geburtsh Frauenheilk 2014; 74 : 928-932 @ Georg Thieme Verlag KG Stuttgart · New York . ISSN 0016-5751

\section{Correspondence}

Dr. Dietmar Spitzer

IVF Zentren Prof Zech Salzburg Innsbrucker Bundesstrasse 35 5020 Salzburg

Austria

d.spitzer@salzburg.ivf.at

\section{Abstract \\ $\nabla$}

Introduction: Diminished ovarian reserve (DOR) has been linked to certain subpopulations and distinct gene polymorphisms. It has even been hypothesized that the ABO blood group system could be linked to ovarian reserve (OR) as reflected by early follicular phase follicle stimulating hormone (FSH) levels. Although estimation of $\mathrm{OR}$ is routinely done using levels of anti-Müllerian hormone $(\mathrm{AMH}), \mathrm{FSH}$, estradiol or inhibin $\mathrm{B}$, the diagnostic accuracy of these markers is often limited. The aim of this study was to evaluate whether there is any correlation between IVF patients' ABO blood group system and ART outcome. Methods: In this retrospective observational single-center study we investigated the outcome of 1889 IVF cycles carried out between 2005 and 2012 with regard to blood type and OR in different age groups (21-36 years and 37-43 years). The number of cumulus oocyte complexes (COCs) and metaphase II oocytes obtained after ovarian stimulation, fertilization rate (FR), pregnancy rate (PR) and birth rate (BR) were evaluated with respect to maternal age (21-36 and 37-43 years, respectively).

Results: We found no significant differences in the average number of COCs after ovum pick-up in either of the age groups. Moreover, the mean number of MII oocytes and 2PN stages were similar for all blood type groups. As regards IVF outcome measured in terms of PR and BR, no significant differences were observed between the different blood groups. In conclusion, no correlation was found between blood type and female fertility.

Discussion: The most precise definition of OR is determining the number of competent oocytes. Based on the finding of our study, the hypothesis that there is a correlation between $\mathrm{OR}$ and $\mathrm{ABO}$ blood group system can be dismissed for Caucasian IVF patients.

\section{Zusammenfassung \\ $\nabla$}

Einleitung: Diverse genetische Polymorphismen oder bestimmte Subpopulationen sind bisher mit einer verminderten ovariellen Reserve (OR) in Verbindung gebracht worden. Auch ein Zusammenhang zwischen ovarieller Reserve und Blutgruppenzugehörigkeit wurde postuliert. Obwohl die OR routinemäßig entweder über die Anti-Müller-Hormon-(AMH-)Serumkonzentration oder die Konzentration des follikelstimulierenden Hormons (FSH), des Östradiols oder über Inhibin B bestimmt wird, ist die diagnostische Aussagekraft dieser prognostischen Marker limitiert. Ziel dieser Studie war es, herauszufinden, ob eine mögliche Korrelation zwischen den Blutgruppenmerkmalen (AB0-System) und dem ART-Outcome bei IVF-Patientinnen besteht und ob damit Rückschlüsse auf die OR zu ziehen sind.

Methoden: In einer retrospektiven Single-Center-Observationsstudie wurden zwischen den Jahren 2005 und 2012 insgesamt 1889 IVF-Zyklen ausgewertet und deren Ergebnis in Hinblick auf Blutgruppenzugehörigkeit und $\mathrm{OR}$ in unterschiedlichen Altersgruppen (21-36 Jahre bzw. 37-43 Jahre) analysiert. Die Anzahl der nach der ovariellen Stimulation erhaltenen Kumulus-Oozyten-Komplexe (KOK) und Metaphase-II-Oozyten, sowie die Fertilisierungs-, Schwangerschaftsund Geburtenrate wurden im Hinblick auf das Alter der Patientinnen (21-36 bzw. 37-43 Jahre) evaluiert.

Ergebnisse: In beiden analysierten Altersgruppen wurden keine signifikanten Unterschiede hinsichtlich der durchschnittlichen nach der Punktion erhaltenen KOK festgestellt. Darüber hinaus waren die mittlere Anzahl der MII-Oozyten und nach der Fertilisierung erhaltenen 2PN-Stadien in allen Blutgruppen gleich. Auch konnten keine wesentlichen Unterschiede in den Schwangerschafts- und den Geburtenraten zwischen den verschiedenen Blutgruppen in beiden Alterskol- 
lektiven festgestellt werden. Es konnte keine Korrelation zwischen Blutgruppenzugehörigkeit und weiblicher Fertilität beobachtet werden.

Diskussion: Die präziseste Methode zur Festlegung der OR ist die Bestimmung der Anzahl kompetenter Oozyten im IVF-Zyklus. Nach unseren Ergebnissen kann die Hypothese einer Korrelation zwischen OR und dem AB0-Blutgruppensystem verworfen werden.

\section{Introduction}

Ovarian reserve (OR) is the term used to describe the functional potential of the ovaries and it is considered to reflect the quantity and quality of oocytes within the ovaries [1]. Ovarian reserve is closely linked to reproductive capacity and is largely determined by female age. With the implementation of reproductive medicine, interest has focused on OR with the aim of (i) improving the safety of ovarian stimulation procedures by identifying high responder patients (who have an elevated risk of developing ovarian hyperstimulation syndrome [OHSS]), (ii) improving the efficacy of ovarian stimulation procedures (by adjusting the stimulation dose), and (iii) using OR as a tool to predict the outcome of IVF treatment.

The age-linked decline of OR is attributed to the loss of follicles in the ovary and a decrease in oocyte quality, which mirrors the decreased reproductive potential of women over time. Nevertheless, despite its definition, assessment of OR remains difficult. It is now well accepted that the age-related decline in OR is not uniform for all women. Women of similar ages can respond quite differently to ovarian stimulation. Various tests have been developed and, apart from determining FSH (follicle-stimulating hormone) concentrations and inhibin B serum levels, the most accepted methods for OR determination currently involve (i) investigation of anti-Müllerian hormone (AMH) levels, and (ii) antral follicle count (AFC) by transvaginal ultrasound (TVUS). However, the reliability of these methods to determine OR is still debated. However, as OR is considered an important parameter for the prognosis of IVF success, obtaining a good estimate and guidelines for the optimal dose of ovarian stimulation would be extremely useful [2]. Various studies have previously suggested that AB0 blood group antigens could be linked to distinct diseases that have a partially genetic basis [3-4]. Moreover, some studies have reported an association between blood group $A$ and an increased incidence of OHSS [5-6]. It was hypothesized that elevated risk for OHSS in blood group A patients compared to women with blood group 0 might be due to previously observed differences in von Willebrand factor (vWF) and factor VIII concentrations, which seem to be genetically determined. A recently published study by Nejat et al. also suggested a relationship between blood type and OR. The authors found that patients with blood type 0 were twice as likely to exhibit FSH levels $>10 \mathrm{mIU} / \mathrm{ml}$ compared to those with A or AB blood types [7]. Given the elevated baseline FSH levels of IVF patients with blood group 0, the authors concluded that this subpopulation has a diminished ovarian reserve (DOR). However, the data for this is contradictory [8-9].

The aim of this study was to evaluate whether different blood types in IVF patients can be linked to outcomes of ART treatment. We analyzed the number of oocytes obtained during oocyte pickup (OPU), oocyte competence with regard to the number of retrieved metaphase II (MII) oocytes, fertilization rate (FR), and IVF outcome as reflected by pregnancy rates (PR) and birth rates (BR).

\section{Method}

\section{Patients and study design}

Our study included data from 1889 IVF cycles and 1202 patients who underwent fresh embryo transfer (ET) between December 2005 and November 2012. Only Caucasian patients were included in this study; no other inclusion or exclusion criteria were used. Patients lost to follow-up were excluded. All patients signed an informed consent form for the use of outcome data. Patients were grouped according to age (group I consisted of patients between 21 and 36 years, group II of patients between 37 and 43 years) and blood type (AB0 system and Rhesus factor). The cutoff age selected for this study was 37 years, based on the criteria cited by Kaur and Arora [10].

\section{Ovarian stimulation and embryo culture}

In the majority of IVF cycles, the long protocol (LP) was used for ovarian stimulation [11]. A few patients were stimulated using the short (SP) or the antagonist protocol (AP) [12-13]. The oocytes were retrieved 36 hours after human chorionic gonadotropin (hCG) administration. Fertilization was done either by standard insemination (IVF), intracytoplasmic sperm injection (ICSI) or intracytoplasmic morphologically selected sperm injection (IMSI) [14]. Embryos were kept in global embryo culture medium (LifeGlobal, Ontario, Canada) supplemented with human serum albumin (HSA) (LifeGlobal, Ontario, Canada) in four-well dishes (Nunc A/S, Roskilde, Denmark) [11]. The number of cumulus oocyte complexes (COCs) and MII oocytes retrieved by ovarian puncture was evaluated. Normally fertilized (two pronuclei) oocytes were assessed 16 hours after insemination or sperm injection. Only the first IVF cycle of each patient was used for this analysis.

\section{Clinical outcome}

Pregnancy rate was determined by testing for urinary $\beta$-hCG 14 days after embryo transfer for all IVF cycles. The rate of ongoing pregnancies (oPR) was defined as detection of fetal heartbeat on ultrasound at 8-12 weeks after ET. Birth rate (BR) was calculated based on the ratio between delivery and ET.

\section{Statistics}

Statistical analysis was performed using the Statistical Package for the Social Sciences (SPSS) software, version 17.0 for Windows (SPSS Inc., Chicago, IL, USA). One-way ANOVA test was used to test for statistical differences in the patient characteristics "age" and "body mass index" (BMI). The statistical significance of differences in the distribution of variables including Rhesus (Rh) factor, type of ovarian stimulation, fertilization technique, PR, oPR, and BR between blood group types was evaluated using Pearson's chi-squared test. Differences in the number of COCs, MII oocytes and fertilized oocytes between groups were evaluated by multivariate regression analysis. Differences were considered statistically significant when $\mathrm{p}$ was $<0.05$. 
Table 1 Patient characteristics and IVF outcome for age group I (21-36 years). Patients' characteristics: mean number of cumulus oocyte complexes (COCs) and metaphase II (MII) oocytes obtained after ovarian puncture as well as two pronuclei (2PN) observed $16 \mathrm{~h}$ after fertilization in the age group between 21 and 36 years differentiated according to blood type. Values are numbers (percentages) unless otherwise stated. Age, BMI, COCs, MII oocytes and fertilized oocytes (2PN) are given as means; standard deviation is shown in brackets $( \pm)$. There were no statistically significant differences between the different groups for any of the parameters.

\begin{tabular}{|c|c|c|c|c|c|}
\hline \multicolumn{6}{|l|}{ Patients ( $n=658$ ) } \\
\hline Blood group antigen & 0 & A & B & $A B$ & \\
\hline Patients & 244 & 291 & 86 & 37 & \\
\hline Age (y) & $\begin{array}{l}31.9 \\
( \pm 3.4)\end{array}$ & $\begin{array}{l}32.5 \\
( \pm 3.2)\end{array}$ & $\begin{array}{l}31.7 \\
( \pm 3.3)\end{array}$ & $\begin{array}{l}31.9 \\
( \pm 3.8)\end{array}$ & n.s. \\
\hline $\operatorname{BMI}\left(\mathrm{kg} / \mathrm{m}^{2}\right)$ & $\begin{array}{l}22.7 \\
( \pm 3.7)\end{array}$ & $\begin{array}{l}22.9 \\
( \pm 4.2)\end{array}$ & $\begin{array}{l}23.0 \\
( \pm 4.0)\end{array}$ & $\begin{array}{l}23.7 \\
( \pm 3.8)\end{array}$ & n.s. \\
\hline Rh positive (\%) & $\begin{array}{l}190 \\
(77.9)\end{array}$ & $\begin{array}{l}254 \\
(84.2)\end{array}$ & $\begin{array}{l}73 \\
(84.9)\end{array}$ & $\begin{array}{l}34 \\
(91.9)\end{array}$ & n.s. \\
\hline Rh negative (\%) & $\begin{array}{l}54 \\
(22.1)\end{array}$ & $\begin{array}{l}46 \\
(15.8)\end{array}$ & $\begin{array}{l}13 \\
(15.1)\end{array}$ & $\begin{array}{l}3 \\
(8.1)\end{array}$ & n.s. \\
\hline \multicolumn{6}{|l|}{$\begin{array}{l}\text { Type of ovarian } \\
\text { stimulation (\%) }\end{array}$} \\
\hline L LP & $\begin{array}{l}234 \\
(95.9)\end{array}$ & $\begin{array}{l}281 \\
(96.6)\end{array}$ & $\begin{array}{l}79 \\
(91.9)\end{array}$ & $\begin{array}{l}33 \\
(89.2)\end{array}$ & n.s. \\
\hline - SP & $\begin{array}{l}7 \\
(2.9)\end{array}$ & $\begin{array}{l}5 \\
(1.7)\end{array}$ & $\begin{array}{l}5 \\
(5.8)\end{array}$ & $\begin{array}{l}1 \\
(2.7)\end{array}$ & n.s. \\
\hline - $\mathrm{AP}$ & $\begin{array}{l}3 \\
(1.2)\end{array}$ & $\begin{array}{l}5 \\
(1.7)\end{array}$ & $\begin{array}{l}2 \\
(2.3)\end{array}$ & $\begin{array}{l}3 \\
(8.1)\end{array}$ & n.s. \\
\hline \multicolumn{6}{|l|}{ Fertilization (\%) } \\
\hline > ICSI/IMSI & $\begin{array}{l}232 \\
(95.1)\end{array}$ & $\begin{array}{l}276 \\
(94.8)\end{array}$ & $\begin{array}{l}83 \\
(96.5)\end{array}$ & $\begin{array}{l}34 \\
(91.9)\end{array}$ & n.s. \\
\hline - IVF & $\begin{array}{l}12 \\
(4.9)\end{array}$ & $\begin{array}{l}15 \\
(5.2)\end{array}$ & $\begin{array}{l}3 \\
(3.5)\end{array}$ & $\begin{array}{l}3 \\
(8.1)\end{array}$ & \\
\hline COCs & $\begin{array}{l}11.2 \\
( \pm 5.7)\end{array}$ & $\begin{array}{l}10.8 \\
( \pm 5.6)\end{array}$ & $\begin{array}{l}11.5 \\
( \pm 6.5)\end{array}$ & $\begin{array}{l}10.4 \\
( \pm 4.8)\end{array}$ & n.s. \\
\hline Mll oocytes & $\begin{array}{l}9.7 \\
( \pm 5.1)\end{array}$ & $\begin{array}{l}9.3 \\
( \pm 4.9)\end{array}$ & $\begin{array}{l}9.7 \\
( \pm 5.4)\end{array}$ & $\begin{array}{l}8.9 \\
( \pm 4.3)\end{array}$ & n.s. \\
\hline Fertilized oocytes & $\begin{array}{l}7.6 \\
( \pm 4.3)\end{array}$ & $\begin{array}{l}7.1 \\
( \pm 4.0)\end{array}$ & $\begin{array}{l}7.5 \\
( \pm 4.4)\end{array}$ & $\begin{array}{l}6.7 \\
( \pm 3.8)\end{array}$ & n.s. \\
\hline
\end{tabular}

BMI: body mass index; COCs: cumulus oocyte complexes; MII: metaphase II; ICSI: intracytoplasmic sperm injection; IMSI: intracytoplasmic morphologically selected sperm injection; IVF: in vitro fertilization; LP: protocol; SP: short protocol; AP: antagonist protocol

\section{Results}

$\nabla$

Patient characteristics

The study included 1202 female IVF patients with an age range between 21 and 43 years (mean $35.8 \pm 4.6$ years). Distribution of blood groups was as follows: 0: $37.4 \%, \mathrm{~A}: 44.4 \%, \mathrm{~B}: 12.5 \% \mathrm{AB}$ : $5.7 \%$. This distribution corresponds to the overall blood group distribution in Central Europe. No differences were found in major confounders such as stimulation protocols or proportion of ICSI/IMSI and IVF cycles. Detailed data are given in $\bullet$ Tables 1 and 2.

\section{Number of COCs, MII oocytes and fertilized oocytes and correlation to blood type}

658 patients between 21 and 36 years were included in age group I ( Table 1). No statistically significant differences in age, BMI or percentage of Rh negative and Rh positive patients were found. Similarly, no statistical differences in the distribution of stimulation protocols or in fertilization techniques used were observed between the ABO groups. A mean of 11.2 COCs were
Table 2 Patient characteristics and IVF outcome for age group II (37-43 years). Patients' characteristics: mean number of cumulus oocyte complexes (COCs) and metaphase II (MII) oocytes obtained after ovarian puncture as well as two pronuclei (2PN) observed $16 \mathrm{~h}$ after fertilization in the age group between 37 and 43 years differentiated according to blood type. Values are numbers (percentages) unless otherwise stated. Age, BMI, COCs, MII oocytes and fertilized oocytes (2PN) are given as means; standard deviation is shown in brackets $( \pm)$. There were no statistically significant differences between the different groups for any of the parameters.

\begin{tabular}{|c|c|c|c|c|c|}
\hline \multicolumn{6}{|l|}{ Patients $(n=544)$} \\
\hline Blood group antigen & $\mathrm{O}$ & A & B & $A B$ & \\
\hline Patients (n) & 206 & 243 & 64 & 31 & \\
\hline Age (y) & $\begin{array}{l}39.3 \\
( \pm 1.7)\end{array}$ & $\begin{array}{l}39.5 \\
( \pm 1.8)\end{array}$ & $\begin{array}{l}39.0 \\
( \pm 1.8)\end{array}$ & $\begin{array}{l}39.6 \\
( \pm 1.6)\end{array}$ & n.s. \\
\hline BMI $\left(\mathrm{kg} / \mathrm{m}^{2}\right)$ & $\begin{array}{l}23.1 \\
( \pm 4.2)\end{array}$ & $\begin{array}{l}22.4 \\
( \pm 3.3)\end{array}$ & $\begin{array}{l}23.1 \\
( \pm 4.3)\end{array}$ & $\begin{array}{l}21.9 \\
( \pm 2.2)\end{array}$ & n.s. \\
\hline Rh positive (\%) & $\begin{array}{l}177 \\
(85.9)\end{array}$ & $\begin{array}{l}206 \\
(84.8)\end{array}$ & $\begin{array}{l}57 \\
(89.1)\end{array}$ & $\begin{array}{l}28 \\
(90.3)\end{array}$ & n.s. \\
\hline Rh negative (\%) & $\begin{array}{l}29 \\
(14.1)\end{array}$ & $\begin{array}{l}37 \\
(15.2)\end{array}$ & $\begin{array}{l}7 \\
(10.9)\end{array}$ & $\begin{array}{l}3 \\
(9.7)\end{array}$ & n.s. \\
\hline \multicolumn{6}{|l|}{$\begin{array}{l}\text { Type of ovarian } \\
\text { stimulation (\%) }\end{array}$} \\
\hline$\checkmark \mathrm{LP}$ & $\begin{array}{l}197 \\
(95.7)\end{array}$ & $\begin{array}{l}229 \\
(94.3)\end{array}$ & $\begin{array}{l}61 \\
(95.3)\end{array}$ & $\begin{array}{l}29 \\
(93.5)\end{array}$ & n.s. \\
\hline$\Rightarrow \mathrm{SP}$ & $\begin{array}{l}5 \\
(2.4)\end{array}$ & $\begin{array}{l}13 \\
(5.3)\end{array}$ & $\begin{array}{l}2 \\
(3.1)\end{array}$ & $\begin{array}{l}2 \\
(6.5)\end{array}$ & n.s. \\
\hline$\checkmark \mathrm{AP}$ & $\begin{array}{l}4 \\
(1.9)\end{array}$ & $\begin{array}{l}1 \\
(0.4)\end{array}$ & $\begin{array}{l}1 \\
(1.6)\end{array}$ & - & n.s. \\
\hline \multicolumn{6}{|l|}{ Fertilization (\%) } \\
\hline - ICSI/IMSI & $\begin{array}{l}199 \\
(96.6)\end{array}$ & $\begin{array}{l}234 \\
(96.3)\end{array}$ & $\begin{array}{l}61 \\
(95.3)\end{array}$ & $\begin{array}{l}30 \\
(96.8)\end{array}$ & n.s. \\
\hline$\Rightarrow$ IVF & $\begin{array}{l}7 \\
(3.4)\end{array}$ & $\begin{array}{l}9 \\
(3.7)\end{array}$ & $\begin{array}{l}3 \\
(4.7)\end{array}$ & $\begin{array}{l}1 \\
(3.2)\end{array}$ & \\
\hline $\mathrm{COCs}$ & $\begin{array}{l}8.6 \\
( \pm 5.2)\end{array}$ & $\begin{array}{l}8.2 \\
( \pm 4.8)\end{array}$ & $\begin{array}{l}9.6 \\
( \pm 6.1)\end{array}$ & $\begin{array}{l}6.9 \\
( \pm 4.9)\end{array}$ & n.s. \\
\hline MII oocytes & $\begin{array}{l}7.2 \\
( \pm 4.6)\end{array}$ & $\begin{array}{l}7.2 \\
( \pm 4.3)\end{array}$ & $\begin{array}{l}8.2 \\
( \pm 5.5)\end{array}$ & $\begin{array}{l}6.1 \\
( \pm 4.3)\end{array}$ & n.s. \\
\hline Fertilized oocytes & $\begin{array}{l}5.5 \\
( \pm 3.5)\end{array}$ & $\begin{array}{l}5.7 \\
( \pm 3.6)\end{array}$ & $\begin{array}{l}6.0 \\
( \pm 3.8)\end{array}$ & $\begin{array}{l}5.0 \\
(+3.9)\end{array}$ & n.s. \\
\hline
\end{tabular}

BMI: body mass index; COCs: cumulus oocyte complexes; MII: metaphase II; ICSI: intracytoplasmic sperm injection; IMSI: intracytoplasmic morphologically selected sperm injection; IVF: in vitro fertilization; LP: protocol; SP: short protocol; AP: antagonist protocol

achieved for patients with blood type $0,10.8$ for patients with blood type A, 11.5 for patients with blood group B, and 10.4 for patients with type $A B$. No statistically significant differences were observed between groups. Subsequently, no differences in the number of MII oocytes or in FR were noted between groups. Age group II included 544 patients between 37 and 43 years ( Table 2). There were no differences in patient characteristics such as mean age, BMI, distribution of Rhesus factor, ovarian stimulation protocol, or fertilization technique. As in the younger patient group, no statistically significant differences in the number of COCs, MII oocytes or fertilized oocytes were observed using multivariate regression analysis.

\section{Pregnancy outcome}

Pregnancy outcome was determined for each age group and blood type ( Tables 3 and 4). In age group I (younger patients), a mean PR of 51.2\% was recorded; however, there were no statistically significant differences between AB0 types. Similarly, oPR and BR did not differ significantly between groups. 
Table 3 Pregnancy outcome for age group I (21-36 years). Pregnancy outcome was differentiated according to blood type for patients between 21 and 36 years. Values are numbers (percentages) unless otherwise stated. The values for age are given as means; standard deviation is given in brackets $( \pm)$. There were no statistically significant differences between the different groups for any of the parameters.

\begin{tabular}{llllll}
$\begin{array}{l}\text { Patients }(\mathbf{n = 6 5 8}) \\
\text { Blood group antigen }\end{array}$ & $\mathrm{O}$ & $\mathrm{A}$ & $\mathrm{B}$ & $\mathrm{AB}$ & \\
\hline Cycles $(\mathrm{n})$ & 370 & 421 & 54 & 123 & \\
Mean age $(\mathrm{y})$ & 31.9 & 32.6 & 31.3 & 32.1 & n.s. \\
& $( \pm 3.4)$ & $( \pm 3.1)$ & $( \pm 3.8)$ & $( \pm 3.1)$ & \\
\hline Pregnancy rate (\%) & 185 & 218 & 29 & 64 & n. s. \\
& $(50.0)$ & $(51.8)$ & $(53.7)$ & $(52.0)$ & \\
\hline $\begin{array}{l}\text { Ongoing pregnancy } \\
\text { rate }(\%)\end{array}$ & 153 & 179 & 23 & 55 & n.s. \\
\hline Birth rate (\%) & $(41.4)$ & $(42.5)$ & $(42.6)$ & $(44.7)$ & \\
& 140 & 170 & 21 & 49 & n.s. \\
& $(37.8)$ & $(40.4)$ & $(38.9)$ & $(39.8)$ & \\
\hline
\end{tabular}

In group II aged between 39.3 and 39.7 years a mean PR of 34.5\% was observed. However, no statistically significant differences in PR, oPR or BR were found between AB0 groups.

\section{Discussion}

Our findings showed no association between blood group antigens and IVF outcome. We observed no significant differences in the number of MII oocytes retrieved nor in oocyte competence, based on an analysis of fertilization, and no differences in ART outcome in terms of pregnancy and birth rates. These results indicate that IVF patients with a specific blood group do not have a higher incidence of reduced fertility in response to ovarian stimulation - and consequently the hypothesis of DOR in women with blood type 0 can be dismissed. Our observations are in accordance with the findings of Timberlake and colleagues [9] but are in contradiction to the results of Nejat et al. [7]. The strength of our study lies in the large number of participants and in the approach used to analyze patients' fertility potential. Biochemical evidence with determination of singular prognostic markers for DOR was not used to assess fertility potential of patients.

Indirect determination of OR by evaluating hormonal status has several drawbacks. FSH is generally determined by means of a blood test done on cycle day 3 as estrogen levels are expected to be low at this point in time. Estrogen suppresses the production of FSH, acting as a negative feedback mechanism. It is therefore essential to evaluate both hormone levels at the same point in time. The FSH level is only important if estrogen levels are low. In fertile women, FSH levels are typically < $10 \mathrm{mIU} / \mathrm{ml}$ [15]. However, different assays in different laboratories show a wide range for FSH levels. Determination of AMH has been identified as a more useful biochemical test [16-17]. But in some subpopulations such as in women with polycystic ovarian syndrome (PCOS), AMH can be elevated. A combination of AMH concentrations and antral follicle count (AFC) is therefore assumed to be a more reliable method for assessing OR. Nevertheless, OR testing remains a challenge. Broekmans et al. stated that the current tests generally used to determine OR have only a very modest predictive value. Although they are not expensive and not particularly complex, their accuracy in predicting fertility potential and the likelihood of pregnancy is limited [18]. We are of the opinion that our analyzed parameters (mature oocytes, fertilization rate
Table 4 Pregnancy outcome for age group II (37-43 years). Pregnancy outcome was differentiated according to blood type for patients between 37 and 43 years. Values are numbers (percentages) unless otherwise stated. The values for age are given as means; standard deviation is given in brackets $( \pm)$. There were no statistically significant differences between the different groups for any of the parameters.

\begin{tabular}{|llllll|}
\hline $\begin{array}{l}\text { Patients }(\mathbf{n}=\mathbf{5 4 4}) \\
\text { Blood group antigen }\end{array}$ & $\mathrm{O}$ & $\mathrm{A}$ & $\mathrm{B}$ & $\mathrm{AB}$ & \\
\hline Cycles $(\mathrm{n})$ & 363 & 413 & 38 & 107 & \\
\hline Mean age $(\mathrm{y})$ & 39.7 & 39.7 & 39.7 & 39.3 & n.s. \\
& $( \pm 2.0)$ & $( \pm 2.1)$ & $( \pm 1.8)$ & $( \pm 2.0)$ & \\
\hline Pregnancy rate (\%) & 125 & 144 & 13 & 36 & n.s. \\
& $(34.4)$ & $(34.9)$ & $(34.2)$ & $(33.6)$ & \\
\hline $\begin{array}{l}\text { Ongoing pregnancy } \\
\text { rate }(\%)\end{array}$ & 95 & 108 & 11 & 27 & n.s. \\
\hline Birth rate $(\%)$ & $(26.2)$ & $(26.2)$ & $(28.9)$ & $(25.2)$ & \\
& 81 & 91 & 10 & 23 & n.s. \\
\hline
\end{tabular}

and pregnancy rates) provide a better prediction of true female fertility potential.

It should be kept in mind that the variability of reproductive hormone levels could also be related to multiple (sub)populations, and differences in serum levels might be due to different ethnic backgrounds [19]. Thus, AMH or FSH serum levels should be interpreted with caution. The study of Schuh-Huerta and colleagues found different genetic variants of OR markers [20]. Exact assessment of OR is considered to be important for the prediction of success in ART and for calculating hormone doses in ovarian stimulation. Genetic studies have identified dozens of factors which might influence female fertility [21]. Several factors were found to be correlated to DOR. In addition to environmental and lifestyle factors such as obesity, smoking, and exposure to polycyclic aromatic hydrocarbons, specific and multiple genetic factors were found to play a role as well [22-26]. A recent publication indicated that BRCA1 gene mutations - in addition to being associated with an increased risk of breast and ovarian cancer - may also be associated with early depletion of OR [27]. However, results of different studies were conflicting [28].

Several attempts have been made to establish a link between female fertility and blood group types [5-7,29]. A correlation between blood group A and an increased incidence of OHSS was proposed, based on 122 patients hospitalized for OHSS [5]. But another study based on 842 Caucasian women at risk for earlyonset OHSS found no differences in blood group distribution between 56 patients with moderate to severe OHSS and 786 women without OHSS [30].

Three studies investigated a putative association between DOR and patient blood type [7-9]. However, findings were contradictory. All three studies shared the same limitation of small patient cohorts. However, each study used different markers to define $\mathrm{OR}$, making direct comparisons of data rather difficult. In our retrospective observational study, we used a different approach for direct determination of fertility potential. We analyzed ART outcomes for two different age groups and found no significant differences with respect to COCs and MII oocytes, both of which reflect ovarian response. No differences were found between the different blood groups in terms of FR, (o)PR or BR. We are therefore of the opinion that the hypothesis that IVF patients with blood group 0 might have a lower OR is contradicted by our findings, as our analyzed parameters offer a better prediction of patients' true fertility potential. Our caveat is that these findings are limited to Caucasian patients. 
Nejat and colleagues observed a relationship between blood group antigens and DOR, irrespective of age; unfortunately the study did not report on the ethnicity of the analyzed subpopulation [7]. Interestingly, the authors mentioned a possible role for glycosyltransferases or a genetic inheritance as a possible explanation [7]. As a second possibility, they hypothesized that unidentified genes or alleles related to ovarian reserve may be linked to $A B O$ loci, suggesting that unidentified variants close to $A B O$ could theoretically explain the observed correlation between blood type and prediction of ovarian reserve, a hypothesis that needs further investigation. This suggestion is of particular interest as a putative candidate gene for DOR was found: steroidogenic factor 1 (SF-1, also known as NR5A1). Mutations of this gene (which is located proximally to the $A B O$ locus) have been reported to be associated with ovarian insufficiency [31].

However, as Nejat and colleagues already stated, the recombination distance between NR5A1 and ABO locus allows for a relatively high probability of recombination between both gene loci, making it very unlikely that the explanation for their findings was a NR5A1 polymorphism. It should also be noted that the ABO antigens reflect an old polymorphism shared by many primates [32]. If a mutation or polymorphism of an unidentified gene responsible for DOR and linked to the $A B O$ locus exists, it is most likely to be younger than the $A B O$ locus. Thus, if such a mutation exists, while it might be spread over a few subpopulations, it would not be spread across all carriers of the $O$ antigen.

In conclusion, we suggest that any correlation between OR and blood type can be neglected.

\section{Conclusion}

\section{$\nabla$}

Caucasian female IVF patients are not at higher risk for impaired ovarian reserve according to blood type. Testing for OR remains difficult. There is a high probability of misinterpretation, especially when analyzing individual parameters. We propose that the first cycle of IVF should be done without prior testing, with the result of the ovarian response acting as a confirmation of the test.

\section{Conflict of Interest}

$\nabla$

None.

\section{References}

1 Macklon NS, Fauser BC. Ovarian reserve. Semin Reprod Med 2005; 23: 248-256

2 Maheshwari A, Fowler P, Bhattacharya S. Assessment of ovarian reserve - should we perform tests of ovarian reserve routinely? Hum Reprod 2006; 21: 2729-2735

3 Sharara AI, Abdul-Baki H, ElHajj I et al. Association of gastroduodenal disease phenotype with $\mathrm{ABO}$ blood group and Helicobacter pylori virulence-specific serotypes. Dig Liver Dis 2006; 38: 829-833

4 Jenkins PV, O'Donnell JS. ABO blood group determines plasma von Willebrand factor levels: a biologic function after all? Transfusion 2006; 46: 1836-1844

5 Binder H, Flegel WA, Emran J et al. Blood group A: an overseen risk factor for early-onset ovarian hyperstimulation syndrome? Reprod Biomed Online 2008; 17: 185-189

6 Binder H, Flegel WA, Emran J et al. Association of blood group A with early-onset ovarian hyperstimulation syndrome. Transfus Clin Biol 2008; 15: 395-401

7 Nejat EJ, Jindal S, Berger D et al. Implications of blood type for ovarian reserve. Hum Reprod 2011; 26: 2513-2517
8 de Mouzon J, Hazout A, Cohen-Bacrie M et al. Blood type and ovarian reserve. Hum Reprod 2012; 27: 1544-1545

9 Timberlake KS, Foley KL, Hurst BS et al. Association of blood type and patient characteristics with ovarian reserve. Fertil Steril 2013; 100: 1735-1739

10 Kaur M, Arora M. Diminished ovarian reserve, causes, assessment and management. Int J Infertility Fetal Med 2013; 4: 45-55

11 Zech NH, Lejeune B, Stecher A et al. A prospective evaluation on the optimal time for selecting a single embryo for transfer: day 3 versus day 5. Fertil Steril 2007; 88: 244-246

12 Loutradis D, Stefanidis K, Drakakis P et al. Comparison between "short" and "long" protocols in an ICSI programme. Eur J Obstet Gynecol Reprod Biol 2005; 120: 69-72

13 Prapas N, Prapas Y, Panagiotidis Y et al. GnRH agonist versus GnRH antagonist in oocyte donation cycles: a prospective randomized study. Hum Reprod 2005; 20: 1516-1520

14 Vanderzwalmen P, Hiemer A, Rubner P et al. Blastocyst development after intracytoplasmic morphologically selected sperm injection (IMSI) is directly correlated with the morphological integrity of human sperm nuclei. Reprod Biomed Online 2008; 17: 617-627

15 Greenseid K, Jindal S, Zapantis A et al. Declining ovarian reserve adversely influences granulosa cell viability. Fertil Steril 2009; 91: 2611-2615

16 Fanchin R, Schonäuer LM, Righini $C$ et al. Serum anti-Müllerian hormone is more strongly related to ovarian follicular status than serum inhibin B, estradiol, FSH and LH on day 3. Hum Reprod 2003; 18: 323327

17 Hazout A, Bouchard P, Seifer DB et al. Serum antimüllerian hormone/ müllerian-inhibiting substance appears to be a more discriminatory marker of assisted reproductive technology outcome than folliclestimulating hormone, inhibin B, or estradiol. Fertil Steril 2004; 82: 1323-1329

18 Broekmans FJ, Kwee J, Hendriks DJ et al. A systematic review of tests predicting ovarian reserve and IVF outcome. Hum Reprod Update 2006; 12: 685-718

19 Tal R, Seifer DB. Potential mechanisms for racial and ethnic differences in antimüllerian hormone and ovarian reserve. Int J Endocrinol 2013; 2013: 818912

20 Schuh-Huerta SM, Johnson NA, Rosen MP et al. Genetic variants and environmental factors associated with hormonal markers of ovarian reserve in Caucasian and African American women. Hum Reprod 2012; 27: 594-608

21 Wood MA, Rajkovic A. Genomic markers of ovarian reserve. Semin Reprod Med 2013; 31: 399-415

22 Malhotra N, Bahadur A, Singh $N$ et al. Does obesity compromise ovarian reserve markers? A clinician's perspective. Arch Gynecol Obstet 2013; 288: 697-703

23 Ye X, Skjaerven R, Basso O et al. In utero exposure to tobacco smoke and subsequent reduced fertility in females. Hum Reprod 2010; 25: 29012906

24 Iliodromiti S, Nelson SM. Biomarkers of ovarian reserve. Biomark Med 2013; 7: 147-158

25 La Marca A, Sighinolfi G, Argento C et al. Polymorphisms in gonadotropin and gonadotropin receptor genes as markers of ovarian reserve and response in in vitro fertilization. Fertil Steril 2013; 99: 970-978.e1

26 Wang TT, Ke ZH, Song Y et al. Identification of a mutation in GDF9 as a novel cause of diminished ovarian reserve in young women. Hum Reprod 2013; 28: 2473-2481

27 Titus S, Li F, Stobezki R et al. Impairment of BRCA1-related DNA doublestrand break repair leads to ovarian aging in mice and humans. Sci Transl Med 2013; 5: 172ra21

28 Michaelson-Cohen $R$, Mor P, Srebnik $N$ et al. BRCA mutation carriers do not have compromised ovarian reserve. Int J Gynecol Cancer 2014; 24 : 233-237

29 Lurie S, Sigler E, Weissman A et al. Association of the Lewis blood-group phenotype with infertility in women. Int J Fertil Womens Med 1998; 43: $155-158$

30 Bellver J, Ferrando M, Garrido $N$ et al. Blood group and ovarian hyperstimulation syndrome. Fertil Steril 2010; 93: 270-271

31 Lourenço D, Brauner R, Lin L et al. Mutations in NR5A1 associated with ovarian insufficiency. N Engl J Med 2009; 360: 1200-1210

32 Ségurel L, Thompson EE, Flutre $T$ et al. The ABO blood group is a transspecies polymorphism in primates. Proc Natl Acad Sci U S A 2012; 109: 18493-18498 